\title{
MEMBRANOUS ATPASES AND TRANSPORT FUNCTIONS OF LYSOSOMES
}

\author{
SHOJI OHKUMA, YoshinoRI MORIYAMA*1, KIYOHISA IINUMA*2, \\ YoshiNOBU MORIMOTO*3, HiROKAZU WATANABE*4, \\ Hidetoshi HAYASHI, Kunizo ARAI \\ AND SAKAe SHIMIZU
}

\begin{abstract}
Department of Biochemistry, Faculty of Pharmaceutical Sciences, Kanazawa University, Takara-machi 13-1, Kanazawa, Ishikawa 920
\end{abstract}

A conspicuous feature of lysosomes is that their interior is acidic providing favorable conditions for acid hydrolases therein. Its precise $\mathrm{pH}$ as well as its maintenance mechanism have long been a matter of dispute. We estimated the intralysosomal $\mathrm{pH}$ using fluorescein isothiocyanate-dextran (FITC-dextran, FD) fluorescence to be slightly lower than 5.0 and showed that it is maintained using metabolic energy (12). We also showed that the intralysosomal acidity is raised by exposure of cells to weak basic substances or acidic ionophores $(12,19,21)$. These findings have attracted attention from a variety of fields, because these chemicals have been known to affect a variety of biologically important phenomena. The interest in the physiological significance of this phenomenon has been strenghthened furthermore by the recent discovery of additional acidic pockets, namely, endosomes, Golgi apparatus, secretory granules, kidney plasmalemmal vesicles, etc. $(2,16,17)$.

\section{PROPERTIES OF LYSOSOMAL PROTON PUMP}

By using FD as a sensitive fluorescent $\mathrm{pH}$ probe, we identified ATP-dependent proton pump $\left(\mathrm{H}^{+}\right.$-pump) on lysosomal membranes, which functions to transport protons into lysosomes $(14,15)$. The lysosomal proton pump is unique both in its sensitivity to NEM, NBD-Cl, quercetin, ADP, AMP-PNP and DCCD and in its insensitivity to oligomycin, vanadate and ouabain. Table 1 summarizes the characteristics of the proton pump on rat liver lysosomes.

\footnotetext{
*1 Present address: Institute of Scientific and Industrial Research, Osaka University, Ibaragi, Osaka 567.

*2 Present address: Kita Hospital, Sango-cho, Ikoma-gun, Nara 636.

*3 Present address: Research and Development, Dai-ichi Pharmaceutical Co. Ltd., Tokyo 103.

*4 Present address: Research and Development, Nippon Zeora Co. Ltd., Kanagawa 229.

Abbreviations used: AMP-CPP: $\alpha, \beta$-methylene-ATP: AMP-PCP: $\beta, \gamma$-methylene-ATP: AMPPNP: adenylyl-imidodiphosphate, ATP: adenosine-5'-triphosphate, DCCD: $N, N^{\prime}$-dicyclohexylcarbodiimide, DES: diethylstilbestrol, DIDS: 4, 4'-diisothiocyanatostilbene-2, $2^{\prime}$-disulphonic acid, FD: fluorescein isothiocyanate-dextran, FCCP: carbonylcyanide $p$-trifluoromethoxyphenylhydrazone, $\mathrm{IC}_{50}$ ': concentration for $50 \%$ of maximum inhibition, NBD-Cl: 7-Chloro-4-nitrobenzo-2-oxa-1, 3diazole, NEM: $N$-ethylmaleimide, PCMB: $p$-chloromercuribenzoic acid, SITS: 4-acetoamide-4'isothiocyanatostilbene-2, 2'-disulfonic acid.
} 
TABLE 1. Properties of lysosomal proton pump as revealed with fuorescein-isothiocyanate dextran fluorescence.

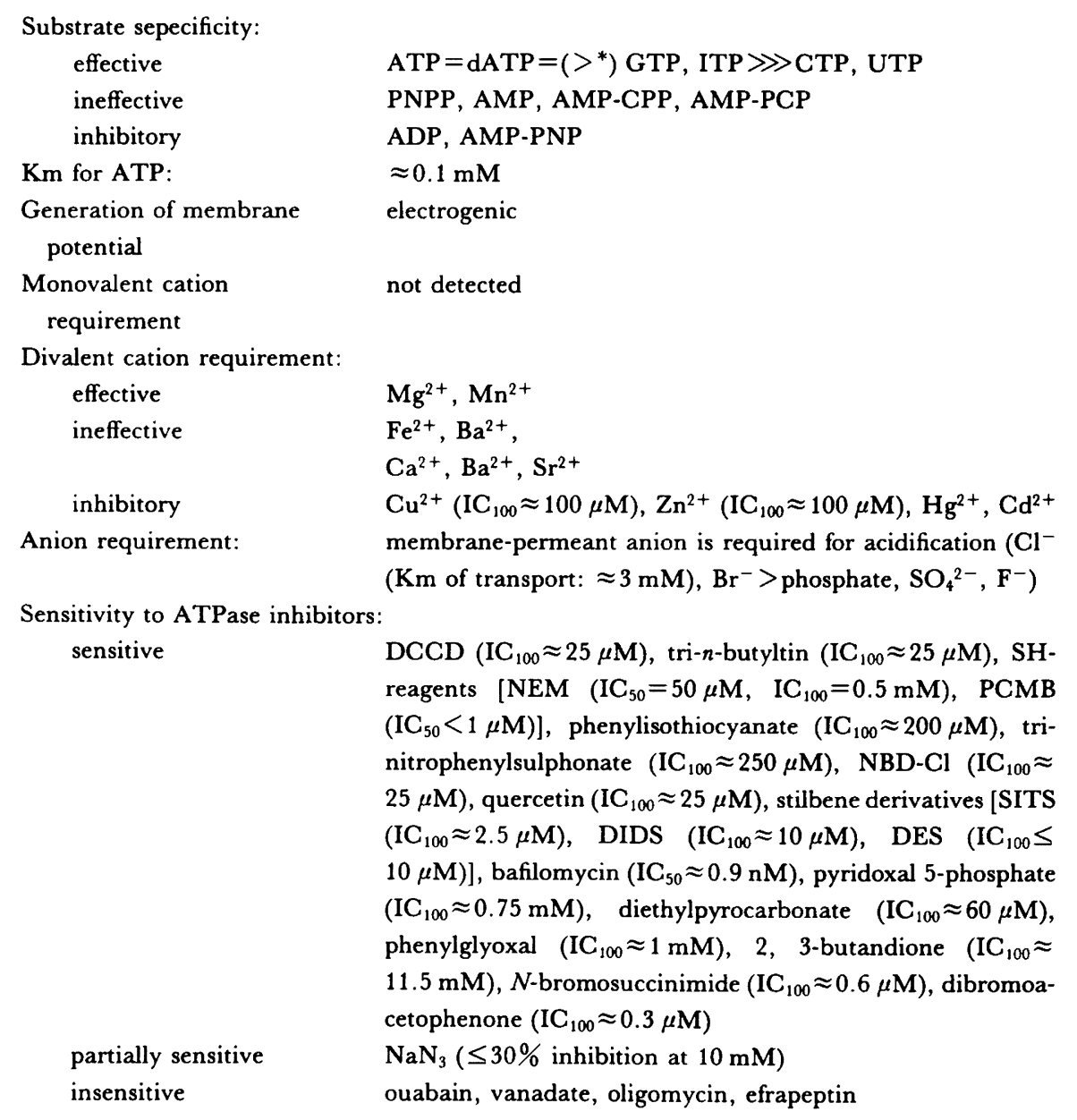

* rat liver tritosomes

\section{PROPERTIES OF ENDOSOMAL PROTON PUMP}

Since our discovery of the lysosomal proton pump, a number of papers have appeared on proton pump activities on various membranes of the vacuolar system (1, $20)$. Fig. 1 shows some of our results on the properties of the proton pump on endosomes (late endosomes) isolated from cultured mouse peritoneal macrophages. Its characteristics are quite similar to those of the lysosomal proton pump.

\section{PROPERTIES OF LYSOSOMAL ATPASES}

We showed that alkaline $\mathrm{Mg}^{2+}$-ATPase activity is associated with the membrane ghosts derived from rat liver lysosomes. Its characteristics show some similarity with those of the proton pump (10). Other unpublished characteristics are as follows: It is 

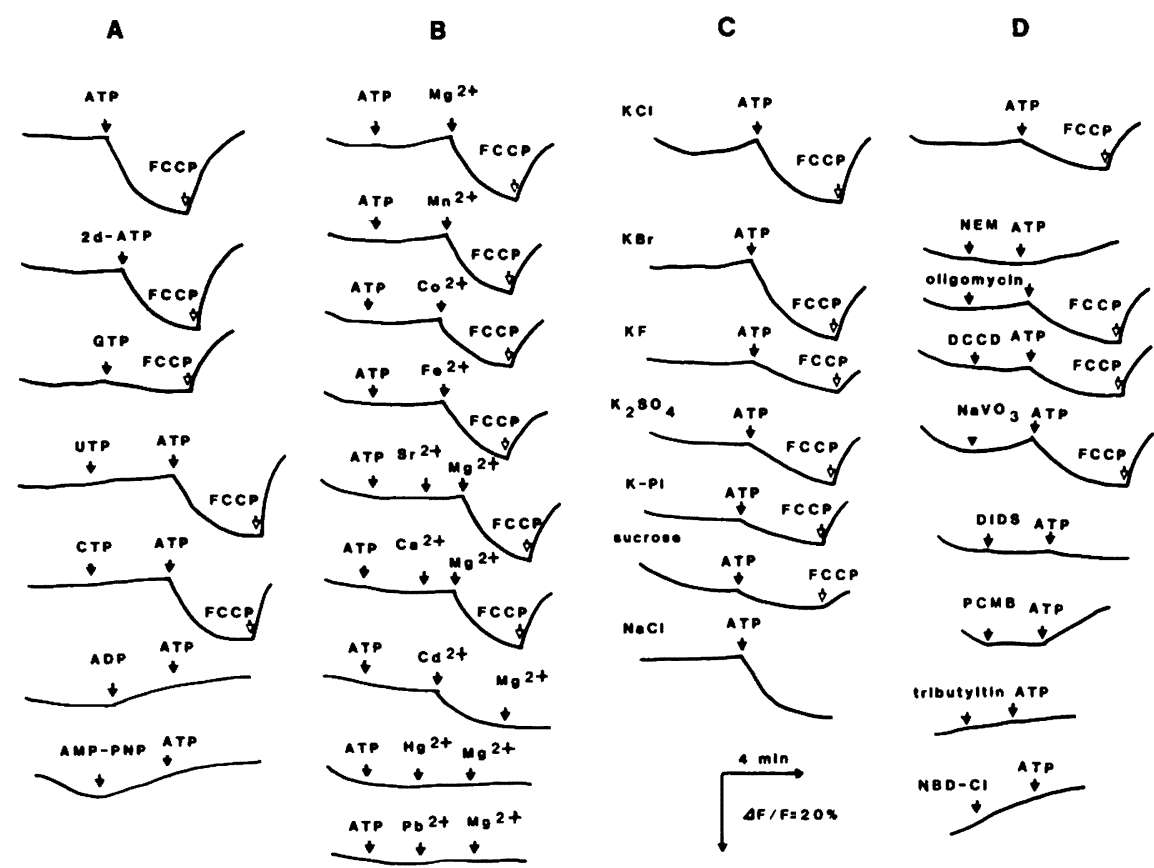

Fig. 1. Selected properties of endosomal proton pump as revealed with FD fluorescence. A) substrate specificity, B) Divalent cation requirement, C) anion requirement, D) inhibitor sensitivity. Late endosome fractions containing FD were obtained from cultured mouse peritoneal macrophages and separated on Percoll density gradient centrifugation and its proton pump activity was determined fluorometrically (20). Nucleotides, $1 \mathrm{mM}$; FCCP, $2.5 \mu \mathrm{M}$; metals, $1 \mathrm{mM}$ as chloride; salts, $0.1 \mathrm{M}$; sucrose, $0.3 \mathrm{M}$; NEM, $1 \mathrm{mM}$; oligomycin, $5 \mu \mathrm{M}$; DCCD, $25 \mu \mathrm{M} ; \mathrm{NaVO}_{3}$, $5 \mathrm{mM}$; DIDS, $50 \mu \mathrm{M}$; PCMB, $10 \mu \mathrm{M}$; tributyltin, $5 \mu \mathrm{M}$; NBD-Cl, $100 \mu \mathrm{M}$.

slightly accelerated by FCCP and nigericin but not by valinomycin, sensitive to phenylglyoxal (maximum $26 \%$ inihbition at $8 \mathrm{mM}$ ), $N$-bromosuccinimide $\left(\mathrm{IC}_{50}\right.$ $=0.22 \mathrm{mM})$, diethylpyrocarbonate $\left(\mathrm{IC}_{50}=0.22 \mathrm{mM}\right)$, dibromoacetophenone $(\max -$ imum $26 \%$ inhibition at $1 \mathrm{mM})$, tetracaine $\left(\mathrm{IC}_{50}=4.0 \mathrm{mM}\right)$, but insensitive to pyridoxal phosphate.

However, there are some differences between the proton pump and ATPase in sensitivity to chemicals: namely, in contrast to proton pump activity, ATPase activity is only marginally sensitive to SH-reagents [NEM (maximum $\approx 20 \%$ inhibition at $1 \mathrm{mM}$ with $\mathrm{IC}_{50}{ }^{\prime}=0.1 \mathrm{mM}$ ) or PCMB (no inhibition)] and bafilomycin (maximum $\approx 10 \%$ inhibition with $\mathrm{IC}_{50}{ }^{\prime}=10 \mathrm{nM}$ ), and almost insensitive to $\mathrm{NBD}-\mathrm{Cl}$, quercetin, stilbene derivatives [SITS, DIDS, DES, dienestrol, hexestrol] and pyridoxal phosphate. Furthermore, ATPase activity is expressed even with $\mathrm{Ca}^{2+}$ as divalent cation.

Such being the case, we looked into the properties of ATPase activities of other sources of lysosomes, namely rat kidney. Fig. 2 shows selected properties of $\mathrm{Mg}^{2+}$. ATPase on rat kidney lysosomes. Kidney ATPase activity showed the $\mathrm{pH}$ profile 

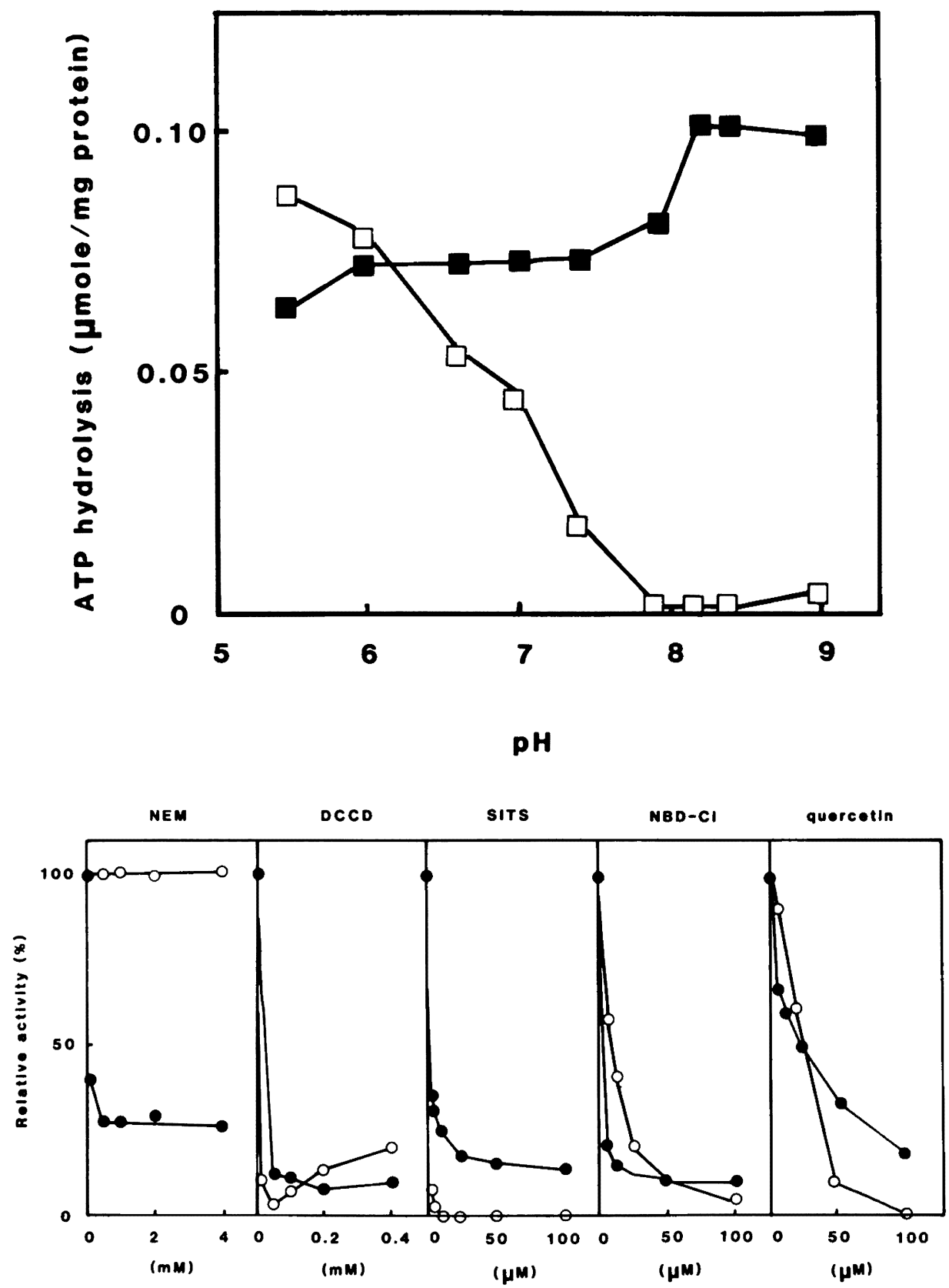

FIc. 2. Selected properties of ATPase activity on lysosomal membrane ghosts of rat kidney. A) $\mathrm{pH}$ profile in the presence ( $\square$ ) and absence (a) of $2 \mathrm{mM} \mathrm{MgCl}_{2}$. B) Inhibitor sensitivity of lysosomal ( $\bullet$ ) as compared with rat kidney submitochondrial particle (O) ATPase. Rat kidney lysosomes and their membrane ghosts were prepared according to (8) and (10). 
(Fig. 2A), the nucleotide specificity (ATP : 2-deoxy-ATP : GTP : ITP : UTP : CTP : ADP : AMP : AMP-PNP $=100: 83: 56: 56: 28: 27: 35: 6: 8)$ and the divalent cation specificity $\left(\mathrm{Mg}^{2+}: \mathrm{Mn}^{2+}: \mathrm{Co}^{2+}: \mathrm{Ca}^{2+}: \mathrm{Zn}^{2+}: \mathrm{Cd}^{2+}:\right.$ none $=100: 74: 18: 14:$ $6: 3: 3)$ similar to those of liver enzyme. Monovalent cation requirement was not detected. However, in contrast to liver enzyme, it was highly sensitive to NEM (maximum $70 \%$ inhibition with $\mathrm{IC}_{50}{ }^{\prime}=4 \mu \mathrm{M}$ ), PCMB (maximum $50 \%$ inhibition with $\mathrm{I}$ $\mathrm{C}_{50}{ }^{\prime}=0.5 \mu \mathrm{M}$ ), DCCD, NBD-Cl, quercetin, stilbene derivatives (SITS, DIDS (IC 50 $<10 \mu \mathrm{M}$ ), DES (maximum 30\% inhibition with $\mathrm{IC}_{50}{ }^{\prime}=5 \mu \mathrm{M}$ )) (Fig. 2B), and activated strongly by bicarbonate and sulfite and slightly by chloride. However, it was insensitive to pyridoxal phosphate like liver enzyme.

We therefore, tried to identify ATPase(s) on polyacrylamide gel. ATPase(s) were solubilized from membranes using $\mathrm{C}_{12} \mathrm{E}_{9}$ as detergent, and analyzed on undenatured polyacrylamide gel electrophoresis (PAGE) by activity staining technique (Fig. 3). Two efrapeptin-insensitive ATPase bands (500-650 KDa [ATPase I] and $360 \mathrm{KDa}$ [ATPase II]) were recognized in liver enzymes, in contrast to apparently single main band $(\approx 650 \mathrm{KDa})$ accompanied by a faint band $(\approx 550 \mathrm{KDa})$ in kidney enzymes. The ATPase I band was highly sensitive to NEM and not expressed when $\mathrm{Mg}^{2+}$ was replaced with low concentration $(10 \mu \mathrm{M})$ of $\mathrm{Ca}^{2+} . \quad\left[{ }^{14} \mathrm{C}\right] \mathrm{DCCD}$, a specific probe for $\mathrm{H}^{+}$-translocating ATPase $\left(\mathrm{H}^{+}\right.$-ATPase), migrated very close to ATPase I band, but bafilomycin-sensitive ATPase activity was hardly detected on PAGE (manuscript in preparation).

ATPase II band of rat liver lysosomes was resistant to NEM and strongly inhibited by $\mathrm{La}^{3+}$ and was expressed even in the absence of $\mathrm{Mg}^{2+}$ and with low concentration of $\mathrm{Ca}^{2+}$. The function of the ATPase II is not clear, at the moment. We investigated the possible $\mathrm{Ca}^{2+}$-pumping activity on rat liver lysosomes with negative results, at least in the condition where $\mathrm{Ca}^{2+}$-pumping activity was detected on polymorphonuclear leucocyte lysosome fractions (9) (manuscript in preparation).

Rat liver

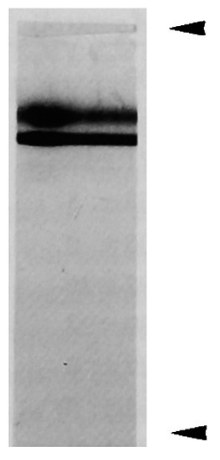

\section{Rat kidney}

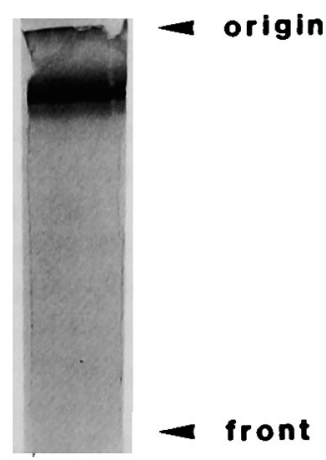

Fic. 3. Activity staining on undenatured polyacrylamide gel of ATPases of lysosomes from two different origins. $\mathrm{Mg}^{2+}$-ATPase activity was stained with lead nitrate method at $\mathrm{pH} 8.5$ in the presence of efrapeptin $(5 \mu \mathrm{g} / \mathrm{ml})$. 


\section{PROPERTIES OF LYSOSOMAL $\mathrm{H}^{+}$-ATPASE}

The clarification of the structure of lysosomal $\mathrm{H}^{+}$-ATPase has been hampered by its highly unstable nature and that it is rather hard to dissociate it from ATPase II. Recently, we have succeeded in its purification from rat liver tritosomes by solubilization with $\mathrm{C}_{12} \mathrm{E}_{9}$ and glycerol density gradient centrifugation and/or preparative gel electrophoresis. It is an NEM-sensitive ATPase with broad $\mathrm{pH}$-activity profile showing several putative subunit proteins on SDS-PAGE including 72, 58, 37, 33, and 16 $\mathrm{KDa}$, of which $16 \mathrm{KDa}$ protein is a $\left[{ }^{14} \mathrm{C}\right] \mathrm{DCCD}$ binding protein.

Recently, the structure and function of the subunit proteins have been clarified for some of the vacuolar type $\mathrm{H}^{+}$-ATPases. These studies suggest that the vacuolar $\mathrm{H}^{+}$-ATPases (V-type ATPases) have structures with both similarities with and differences from those of $\mathrm{F}_{0} \mathrm{~F}_{1}$-type (F-type) $\mathrm{H}^{+}$-ATPases (6). The putative subunit composition we identified on lysosomal $\mathrm{H}^{+}$-ATPase is in good agreement with the hypothesis that the lysosomal $\mathrm{H}^{+}$-ATPase belongs to V-type ATPase. We are currently investigating the reconstitution of proton pump activity using purified enzyme to see if it functions to transport protons across membranes.

\section{TRANSPORT FUNCTIONS OF LYSOSOMES}

Great progress has also been made in the study of other secondary transport functions on lysosomal membranes. They include transport of low molecular weight products of intralysosomal digestion, for example amino acids (basic, neutral and acidic), sugars (glucose, galactose, mannose, sialic acid, aminosugars), nucleosides (adenosine, inosine, uridine), as well as transport of anions (chloride) and cations (potassium) associated with proton movement (7). Transport systems are also sug-

TABLE 2A. Effect of chemicals on the transport activity of rat liver tritosomes for $D$-glucose and $L$ arginine. Rat liver tritosomal membrane vesicles were incubated at $37^{\circ} \mathrm{C}$ for $30 \mathrm{sec}$, filtered through Millipore filter $(0.22 \mu \mathrm{m})$ and their radioactivities remaining on the filter were counted in a liquid scintillation counter.

\begin{tabular}{lrcc}
\hline \multicolumn{1}{c}{ Addition } & conc. & $\begin{array}{c}\text { Uptake of } \\
{\left[{ }^{3} \mathrm{H}\right] \text {-Glucose }} \\
\% \text { of control })\end{array}$ & $\begin{array}{c}\text { Uptake of } \\
{\left[\begin{array}{l}\left.{ }^{3} \mathrm{H}\right] \text { L-Arginine } \\
(\% \text { of control })\end{array}\right.}\end{array}$ \\
\hline None (control) & $100 \mu \mathrm{M}$ & 100 & 100 \\
Phloretin & $1 \mathrm{mM}$ & $67 \pm 12$ & $115 \pm 16$ \\
NEM & $1 \mathrm{mM}$ & $71 \pm 12$ & $102 \pm 19$ \\
PCMB & $100 \mu \mathrm{M}$ & $68 \pm 5$ & $68 \pm 4$ \\
DIDS & $100 \mu \mathrm{M}$ & $103 \pm 0$ & - \\
SITS & $1 \mathrm{mM}$ & $97 \pm 28$ & - \\
Pyridoxal 5-phosphate & $1 \mathrm{mM}$ & $89 \pm 27$ & - \\
$N$-bromosuccinimide & $10 \mathrm{mM}$ & $22 \pm 8$ & $34 \pm 4$ \\
Phenylglyoxal & $100 \mu \mathrm{M}$ & $65 \pm 8$ & - \\
DFP & $1 \mathrm{mM}$ & $86 \pm 2$ & $113 \pm 7$ \\
Diethylpyrocarbonate & $10 \mathrm{mM}$ & $112 \pm 28$ & $80 \pm 7$ \\
NaN & $10 \mathrm{mM}$ & $57 \pm 0$ & $104 \pm 3$ \\
KCN & & $97 \pm 2$ & $111 \pm 16$ \\
\hline
\end{tabular}


TABLE 2B. Effect of non-radioactive substrates on the transport activity of rat liver tritosomes for $L$-arginine and $L$-glutamic acid. See Table $2 A$ for details.

\begin{tabular}{lc|cc}
\hline $\begin{array}{c}\text { Addition } \\
(1 \mathrm{mM})\end{array}$ & $\begin{array}{c}\text { Uptake of } \\
{\left[{ }^{3} \mathrm{H}\right] \text { L-Arginine }} \\
(\% \text { of control })\end{array}$ & $\begin{array}{c}\text { Addition } \\
(1 \mathrm{mM})\end{array}$ & $\begin{array}{c}\text { Uptake of } \\
{\left[{ }^{3} \mathrm{H}\right] \text { L-Glutamic }} \\
\text { acid } \\
(\% \text { of control })\end{array}$ \\
\hline Exp. 1 & & Exp. 2 & \\
None (control) & 100 & None (control) & 100 \\
L-Arginine & $46 \pm 13$ & L-Glutamic acid & $54 \pm 4$ \\
D-Arginine & $78 \pm 1$ & D-Glutamic acid & $72 \pm 4$ \\
L-Lysine & $68 \pm 0$ & L-Arginine & $85 \pm 1$ \\
L-Glutamic acid & $118 \pm 19$ & L-Leucine & $99 \pm 11$ \\
L-Leucine & $92 \pm 2$ & L-Proline & $111 \pm 1$ \\
L-Methionine & $110 \pm 12$ & Exp. 3 & 100 \\
L-Histidine & $97 \pm 12$ & None (control) & $84 \pm 25$ \\
L-Proline & $200 \pm 49$ & D-Glutamic acid & $95 \pm 9$ \\
& & L-Leucine & $54 \pm 7$ \\
\hline
\end{tabular}

gested on lysosomal membranes for cyanocobalamin (vitamine $\mathrm{B}_{12}$ ) and cholesterol. ATP hydrolysis and consequent generation of $\mathrm{pH}$ - and membrane potential-difference has been shown to be associated with effective egress of some metabolites form lysosomes.

Fig. 4 and Tables 2A and 2B show selected data of our results on the transport activities of lysosomes (tritosomes) for amino acids, sugar, nucleoside and so on. They showed time-dependent, saturable kinetics with substrate specificity (except adenine transport), and inhibited by some chemical modifications, showing the presence of specific carrier molecules on lysosomal membranes. Transport properties of lysosomes for metabolites (e.g. sugars) are also confirmed by a newly established simple assay procedure using FD-fluorescence (manuscript in preparation).

\section{ATP-DEPENDENT LYSIS OF LYSOSOMES AND MEMBRANE FUSION IN CELL-FREE SYSTEM.}

There is another type of important transport function associated with lysosomes, which is mediated by the membrane fusion reactions with lysosomes themselves, endosomes, autophagosomes or secretory granules.

We established a candidate cell-free system for the analysis of lysosomal membrane fusion, where lysosomes are disrupted by the combined addition of basic substances (or acidic ionohpores) and ATP as a consequence of their failure to fuse with each other (submitted for publication). The disruption of lysosomes, which was detected by the release of FD from lysosomes, was a consequence of their osmotic swelling induced by protonated bases (or cations specific for particular ionophores) accumulated within lysosomes by the action of proton pump activity $(3,18)$. Table 3 summarizes the properties of the ATP-dependent lysis of lysosomes. This phenomenon can be regarded as an in vitro manifestation of vacuole formation caused by basic substances or acidic ionophores in vivo (13). 

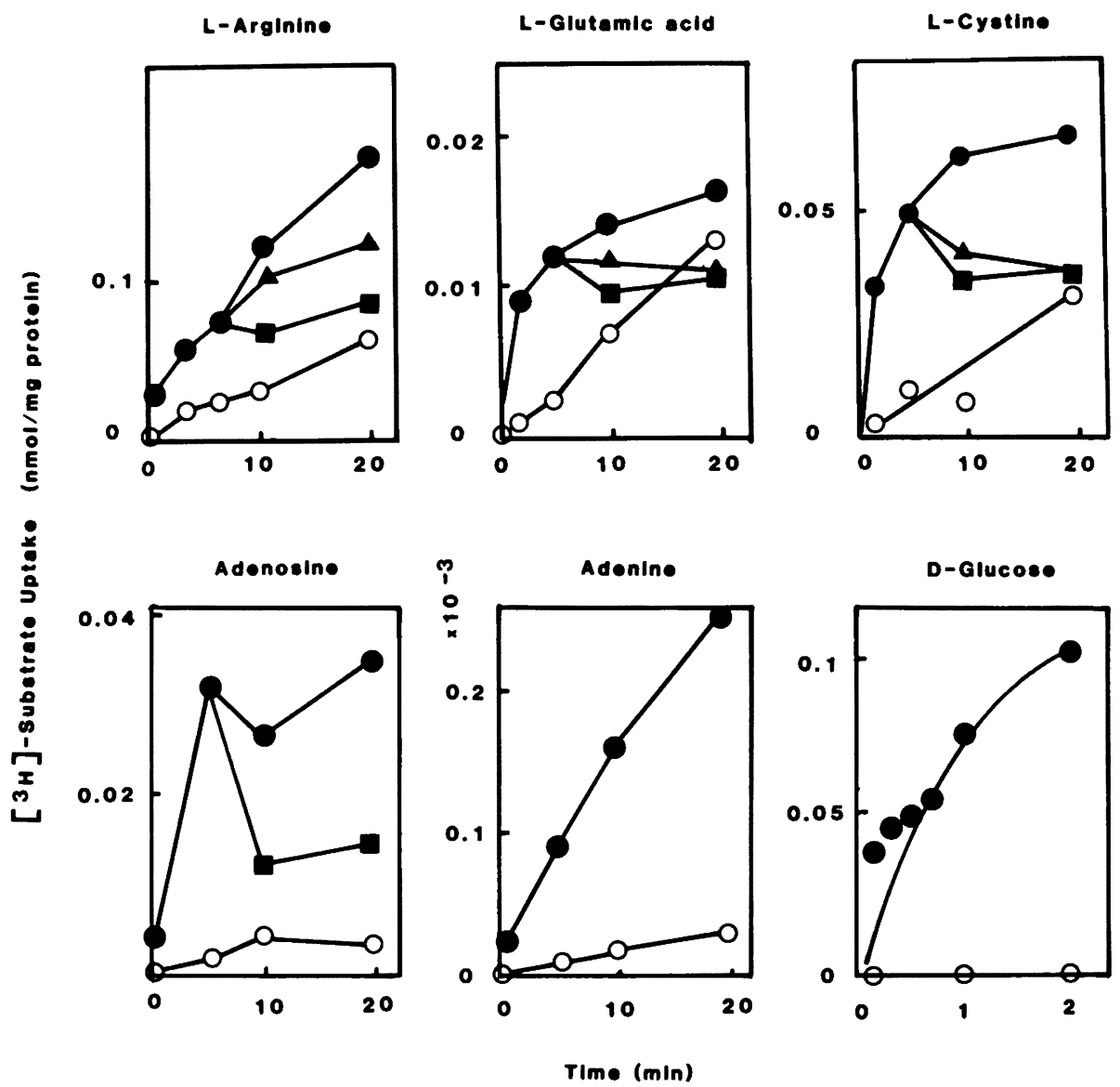

Fic. 4. Time course of uptake into lysosomes of L-arginine, L-glutamic acid, L-cystine, adenosine, adenine and D-glucose. Tritosomal membrane vesicles were incubated at $37^{\circ} \mathrm{C}$ in $0.1 \mathrm{M} \mathrm{KCl}$, $0.2 \mathrm{M}$ sucrose, $40 \mathrm{mM}$ Mops-TMAH ( $\mathrm{pH} \mathrm{7.0)}$ with radiolabelled substrate, collected on Millipore filter $(0.22 \mu \mathrm{m})$ and the radioactivities remaining on the filters were counted in a liquid scintillation counter. $\mathrm{O}: 0^{\circ} \mathrm{C}$, control; $\bullet: 37^{\circ} \mathrm{C}$, control; $\square: 37^{\circ} \mathrm{C}$, + cold $\mathrm{L}$-amino acid or adenosine $(1 \mathrm{mM})$ added at $5 \mathrm{~min} ; \Delta: 37^{\circ} \mathrm{C}$, + cold $\mathrm{D}$-amino acid $(1 \mathrm{mM})$ added at $5 \mathrm{~min}$.

In this system, addition of cytosol suppressed lysosome disruption (Fig. 5). This phenomenon is most reasonably explained by the requirement of cytosolic factor(s) for membrane fusion between lysosomes themselves $(4,13)$. The factor(s) were found to be heat-labile, NEM-resistant proteinaceous substance(s) of high-molecular weight.

Recently, in vitro endosome-lysosome fusion has been reported to require heat labile, NEM-resistant cytosolic factor(s) with similar properties (11), in contrast to the requirement of NEM-sensitive factor for early endosome fusion (5). Membrane-fusion is a prerequisite for the function of vacuolar system and the clarification of its regulatory mechanism should give us useful information for understanding and con- 
TABLE 3. Properties of ATP-dependent lysis of lysosomes induced by basic substances or acidic ionophores.

1. Any of the vacuoligenic bases or acidic ionophores, but none of the non-vacuoligenic bases or neutral ionophores induces disruption of lysosomes.

2. Disruption of lysosomes requires functional proton pump and is inhibited by the inhibitors of lysosomal proton pump including DCCD.

3. Disruption of lysosomes requires permeant anion and is suppressed when permeant anion is replaced with impermeant one.

4. Disruption of lysosomes is also suppressed when the osmotic pressure of suspending medium is increased.

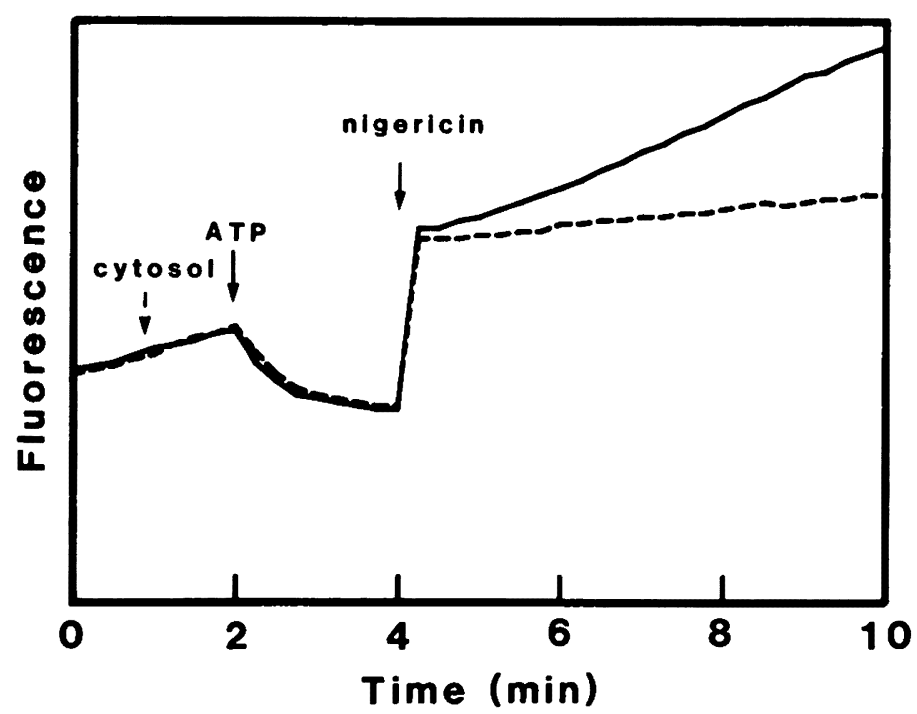

FIG. 5. Effect of cytosol on the ATP-dependent lysis of lysosomes by nigericin. For the details of incubation, see ref. 10 .

trolling multicellular organisms including human beings. Studies of this line are currently in progress in our laboratory.

Another suggestion in the above phenomenon is the possible continuity of lysosomal compartment in vivo, which is disrupted in isolated fractions. In fact, the existence of tubular lysosomes has been reported recently in a variety of cell types (22). The continuity of lysosomal compartment could allow accommodation of a large amount of basic substances within the lysosomal system and its disruption, certainly, should result in osmotic lysis of lysosomes because of limited available volume. Further studies are required and in progress for full explanation of this interesting in vitro phenomenon. 


\section{ACKNOWLEGEMENT}

We are grateful to Mrs. H. Hitomi-Yamada and Mrs. S. Naito-Nakamura, Teikyo University, and Mr. Y. Sai and Mr. M. Neki, Kanazawa University, for technical assistance. This work was supported by the Project Research Fund from the Graduate School of National Science and Technology, Kanazawa University, Sankyo Bioscience Research Fund, Research Fund of Fujisawa Foundation, and a Grant-in-Aid for Scientific Research of Bioenergetics from the Ministry of Education, Science, and Culture of Japan.

\section{REFERENCES}

1. Al-Awqati, Q.: Proton-translocating ATPases. Ann. Rev. Cell Biol. 2; 179-199, 1986.

2. Dean, R. T., W. Jessup. and C. R. Roberts.: Effects of exogenous amines on mammalian cells, with particular reference to membrane flow. Biochem. J. 217; 27-40, 1984.

3. de Duve, C., de Barsy, T., Poole, B., Trouet, A., Tulkens, P. and F. van Hoof.: Commentary: lysosomotropic drugs. Biochem. Pharmacol. 23; 2495-2531, 1974.

4. Deng, Y. and Storrie, B.: Animal cell lysosomes rapidly exchange membrane proteins. Proc. Natl. Acad. Sci. U.S.A. 85; 3860-3864, 1988.

5. Diaz, R., Mayorga, L. S., Weidman, P. J., Rothman, J. E. and Stahl, P. D.: Vesicle fusion following receptor- mediated endocytosis requires a protein active in Golgi transport. Nature 339; 398-400, 1989.

6. Forgac, M.: Structure and function of the vacuolar class of ATP-driven proton pump. Physiol. Rev. 69; 765-796, 1989.

7. Gahl, W. A.: Lysosomal membrane-transport in cellular nutriton. Ann. Rev. Nutr. 9; 39-61, 1989.

8. Harikumar, P. and Reeves, J. P.: The lysosomal proton pump is electrogenic. J. Biol. Chem. 258; 10403-10410. 1983.

9. Klempner, M.S.: An ATP-dependent calcium uptake pump in human neutrophil lysosomes. J. Clin. Invest. 76; 303-310, 1985.

10. Moriyama, Y., Takano, T. and S. Ohkuma.: Proton translocating ATPase in lysosomal membrane ghosts. Evidence that alkaline $\mathrm{Mg}^{2+}$-ATPase acts as a proton pump. J. Biochem. 95; 995-1007, 1984.

11. Mullock, B. M., Branch, W. J., van Schaik, M., Gilbert, L. and Luzio, J. P.: Reconstitution of an endosome-lysosome interaction in cell-free system. J. Cell Biol. 108; 2093-2099, 1989.

12. Ohkuma, S. and Poole, B.: Fluorescence probe measurement of the intralysosomal $\mathrm{pH}$ in living cells and the perturbation of $\mathrm{pH}$ by various agents. Proc. Natl. Acad. Sci. U.S.A. 75; 3327$3331,1978$.

13. Ohkuma, S. and Poole, B.: Cytoplasmic vaculation of mouse peritoneal macrophages and the uptake into lysosomes of weakly basic substances. J. Cell Biol. 90; 656-664, 1981.

14. Ohkuma, S., Moriyama, Y. and Takano, T.: Identification and characterization of proton pump on lysosomes by fluorescein isothiocyanate-dextran fluorescence. Proc. Natl. Acad. Sci. U.S.A. 79; 2758-2762, 1982.

15. Ohkuma, S., Moriyama, Y. and Takano, T.: Electrogenic nature of lysosomal proton pump as revealed with a cyanine dye. J. Biochem. 94; 1935-1943, 1983.

16. Ohkuma, S.: Proton pump of vacuolar system. Seikagaku 56; 1499-1509, 1984.

17. Ohkuma, S.: Endocytosis, $\mathrm{pH}$ and $\mathrm{H}^{+}$-pump. Seibutsu-Buturi $24 ; 119-127,1984$.

18. Ohkuma, S.: Biochemistry of the $\mathrm{pH}$ maintenance mechanism and the proton pump of lysosomes. Yakugaku Zasshi 108; 842-855, 1988. 
19. Ohkuma, S.: The lysosomal proton pump and its effect on protein breakdown. In Lysosomes: Their Role in Protein Breakdown, ed. by H. Glaumann, and F. J. Ballard, Academic Press, London, 1987, pp. 115-148.

20. Ohkuma, S.: Use of fluorescein isothiocyanate-dextran to measure proton pumping in lysosomes and related organelles. In Methods in Enzymology 174, ed. by S. Fleisher and M. Fleisher, Academic Press, New York, 1989, pp. 131-154.

21. Poole, B. and Ohkuma, S.: Effect of weak bases on the intralysosomal $\mathrm{pH}$ in mouse peritoneal macrophages. J. Cell Biol. 90; 665-669, 1981.

22. Swanson, J., Bushnell, A. and Silverstein, S. C.: Tubular lysosome morphology and distribution within macrophages depend on the integrity of cytoplasmic microtubules. Proc. Natl. Acad. Sci. U.S.A. 84; 1921-1925, 1987. 